\title{
Exploring community-based training opportunities for dental therapy students in non-governmental and private sectors in KwaZulu-Natal Province, South Africa
}

\author{
I Moodley, MSc (Dent); S Singh, PhD \\ Discipline of Dentistry, School of Health Sciences, University of KwaZulu-Natal, Durban, South Africa
}

Corresponding author: I Moodley (moodleyil@ukzn.ac.za)

\begin{abstract}
Background. The current health system in South Africa (SA) struggles to meet the healthcare demands of its nation adequately, especially in KwaZuluNatal (KZN) Province, South Africa. Local communities in KZN have long since recognised the need to supplement the public health system by means of community-driven initiatives of non-governmental organisations (NGOs) and the private sector. Projects by these sectors can also provide a platform for experiential learning for dental therapy students.

Objective. To explore learning opportunities for dental therapy students through the community-driven health initiatives of NGOs and the private sector in KZN.

Methods. This qualitative study used face-to-face interviews with key stakeholders organising community-based initiatives in the NGO and private sectors. The interviews were audio-recorded and analysed using thematic analysis. Ethical clearance was obtained from the University of KwaZulu-Natal, Durban, SA.

Results. According to the participants, there were many innovative service delivery modes, ranging from a mobile health bus, a container turned into a clinic, to well-established clinics that provided meaningful learning opportunities for dental students. By participating in these projects, respondents believed that students could gain real-world experiences and a greater sense of social accountability.

Conclusion. This study showed that there are many opportunities in the private and NGO sectors that could provide support for community-driven learning initiatives for undergraduate dental therapy students.
\end{abstract}

Afr J Health Professions Educ 2018;10(3):176-182. DOI:10.7196/AJHPE.2018.v10i3.1031

The current health system in South Africa (SA) struggles to meet the healthcare demands of its nation adequately, especially in KwaZulu-Natal (KZN) Province, SA, where the quadruple disease burden of HIV/AIDS, tuberculosis, chronic illnesses due to unhealthy lifestyles and injuries is increasing. ${ }^{[1]}$ SA has a shortage of healthcare workers, who are unequally distributed between the public and private sectors. ${ }^{[2]}$ The number of public sector healthcare workers are higher in urban than rural areas. ${ }^{[2]}$ KZN has a population of $>10$ million, ${ }^{[3]}$ with only $15 \%$ of them having some medical insurance and using the private sector health services, leaving $85 \%$ of the population dependent on the public health sector for their healthcare needs..$^{[1]}$ Many people from rural and disadvantaged communities have limited access to healthcare, including oral healthcare services. Consequently, many defer treatment for their dental problems, causing long-term effects on their physical and psychological health.

Local communities in KZN have long since recognised the need to intervene, incorporating the government's deficits in social services by means of the philanthropy of donors and the socially aware through non-governmental organisations (NGOs), which are non-profit, nongovernmental entities. ${ }^{[4]}$ They play an integral role in today's society. ${ }^{[4]}$ NGOs include grass-root community-based organisations and faithbased organisations (FBOs), making significant contributions across many fields, such as education and research, social services, health, culture and recreation, law, development and housing. ${ }^{[4]}$
NGOs attempt to supplement the public health service by increasing access to healthcare through service delivery and prevention programmes, as well as raising awareness of the improvement of health outcomes. ${ }^{[4]}$ In KZN, their activities include health awareness, assessment of vital signs, examination and treatment by a medical practitioner, delivery of medication to patients, vision screening and cataract surgery. Oral health services range from oral health education and promotion, dental screenings, tooth extractions for relief of pain and sepsis, restorations, scaling and polishing to specialised work such as correction of cleft palates. These services are performed by health professionals on a voluntary basis and free of charge, in underserved and underinsured communities, helping to reduce the unmet health needs of the province and relieving over-burdened public clinics.

Moreover, private companies become involved in service delivery by providing primary healthcare services to the community on a humanitarian basis, without any intention of making a profit. These community-driven healthcare projects, undertaken by the private sector and NGOs, can also serve as a platform for active student learning by providing opportunities for experiential learning for health professional students. The pedagogy underlying experiential learning is that experiences in authentic situations and environments are transformed into learning experiences through active participation, reflection and internalisation of knowledge. ${ }^{[5,6]}$ Through reflective learning, a student is able to apply theory to practice by connecting classroom teaching and practice in various contexts through 
critical thinking and problem-solving. ${ }^{[7]}$ This type of learning differs from traditional approaches, where knowledge is merely passed down by others.

Karim $^{[8]}$ noted positive clinical, behavioural and attitudinal outcomes when health professional students participated in such projects. These included improved clinical and communication skills, a deeper understanding of the health needs and demands of local communities, enhanced social accountability, inculcation of volunteerism and a sense of moral, ethical and professional responsibility, serving the public well by providing care to all in need, and encouragement of graduates to continue with these new positive behaviours when they qualify.

The Discipline of Dentistry is housed in the College of Health Sciences, University of KwaZulu-Natal (UKZN) and offers an undergraduate training programme in dental therapy. A dental therapist is a mid-level oral healthcare practitioner who provides basic preventive and curative dental care. In SA, the scope of dental therapy practice includes dental (oral) examinations, diagnosis of common oral diseases, scaling and polishing, placement of direct restorations and tooth extractions for child and adult patients. The dental therapist is well suited to meet the oral healthcare needs of the population in both the public and private sectors, in urban and rural communities.

The objective of this study was to explore experiential learning opportunities for dental therapy students through community-driven health initiatives of NGO and private sectors in KZN so that they can benefit from all the identified positive outcomes that might be gained by such participation.

\section{Methods}

\section{Research context}

Clinical training of dental therapy students occurs mainly at a hospital-based setting with community-based training being undertaken in the second semester of the final year. Current community-based activities include a 2-week rotation on board the Phelophepa Health Train, which operates as a mobile healthcare clinic that provides healthcare to impoverished rural communities throughout SA. ${ }^{[9]}$ The Phelophepa project is a private sector initiative that offers health professional students real-world clinical experiences while training. ${ }^{[9]}$ Exposing students to more community settings in addition to hospital training can significantly enhance their clinical training. These settings can provide more authentic environments, which enable experiences to become knowledge ${ }^{[6]}$ and can inculcate in them a deeper sense of social responsibility.

\section{Research design}

This was a qualitative explorative study in which opportunities for community-based training for dental therapy students were explored by engaging with key stakeholders in the private and NGO sectors who are involved in organising community-based initiatives. The study was part of a larger research project conducted on community-based education in the School of Health Sciences, UKZN. Ethical approval was obtained from the Humanities and Social Sciences Research Committee, UKZN (ref. no. HSS/1060/015D).

\section{Participants}

To select interviewees, $3 \mathrm{NGO}$ contacts, known to the researcher, helped to identify more participants through the snowball sampling technique. Eleven different organisations were purposively selected on the basis that their community healthcare projects included the provision of dental services. Of the 11 organisations selected, 9 were NGOs and 2 from private enterprises. The NGOs comprised 8 FBOs and 1 non-profit medical organisation, while the private sector included a dental consumable company and a developmental foundation. An e-mail was sent to each organisation, requesting their participation in the study. Nine responded -8 were NGO representatives and 1 was from the private sector. Participation was voluntary and participants (P1 - P9) provided written informed consent. Participants included medical and dental practitioners, professional nurses and experienced administrative personnel involved in organising community healthcare projects.

\section{Data collection}

Data were collected by means of face-to-face, semi-structured interviews in English, with participants from the NGOs and private sector. The interviews were conducted separately in the offices of the participants - each lasting $\sim 30$ minutes. The researcher developed a set of questions to provide structure to the interviews. The schedule comprised the following questions:

- What current community-based projects are being undertaken by the institution?

- What motivated your institution to undertake this community-based healthcare project?

- What healthcare services are being provided?

- What oral health services are offered?

- How do you choose the community you wish to assist?

- What opportunities exist for dental therapy student participation?

- What are the opportunities and barriers for other student health professionals to participate in this project in a collaborative interdisciplinary team approach?

The interviews were audio-taped and a research assistant transcribed the recordings verbatim and then cleaned them. The researcher engaged the services of a research consultant to assist with the data analysis process. Data coding was done independently by the researcher and research consultant to identify particular features of the data, which were then sorted, allowing themes and sub-themes to emerge from respondents' statements, according to Braun and Clarke's ${ }^{[10]}$ guide to thematic analysis. The data were then compared to develop common themes.

Credibility is a form of internal validity in qualitative research that establishes whether the research findings are genuine and indeed a true reflection of the participants' original views. ${ }^{[10]}$ In this study, credibility was established through peer debriefing, undertaken by another member of the research team, ${ }^{[11,12]}$ who reviewed the data collection methods and processes, transcripts and data analysis procedures, and provided guidance to enhance the quality of the research findings. ${ }^{[1]}$

Transferability, which relates to external validity in qualitative research, was facilitated by providing a thick description of the context of the enquiry and comparing the research findings with those in the current literature. ${ }^{[11]}$ Dependability was achieved by the use of member checks, ${ }^{[11]}$ where the analysed data were sent to a few participants to evaluate the interpretations made by the researcher. Dependability was further enhanced by both the researcher and the research consultant as a co-coder analysing the same data and comparing the results. ${ }^{[1,12]}$ Confirmability was established 
through quotations of actual dialogue of the interviewees. ${ }^{[11]}$ Participant confidentiality and anonymity were maintained.

\section{Results and discussion}

Five main themes emerged from the data analysis process: innovative modes of health service delivery, learning opportunities for dental therapy students, support provided, creating interprofessional learning opportunities and perceived barriers.

\section{Theme 1: Innovative modes of health service delivery}

Participants described innovative ways of service delivery to disadvantaged communities, ranging from the use of storage containers, schools being converted, makeshift clinics to well-established, NGO-sponsored clinics (Table 1).

Although oral health is recognised as a basic human right, the lack of appropriate and affordable dental care is still a major challenge. ${ }^{[13]} \mathrm{In} \mathrm{SA}$, oral diseases are among the most common conditions affecting the population, with dental caries occurring in $90-93 \%$ and periodontal disease in $93.5 \%{ }^{[14]}$ In KZN, Reddy and Singh ${ }^{[15]}$ reported that the caries rate among 6-yearold children increased from $65 \%$ in 2002 to $73 \%$ in 2013, with almost $94 \%$ requiring dental treatment. This places a huge burden on the public health service, with its limited oral health human resources. Given this context, the general public, driven to address the needs of individuals and communities, have reached out informally to assist small groups of people or have organised programmes that could benefit whole communities. ${ }^{[16]}$ This is evident in this study; they used innovative ways in their attempt to strengthen the health system and assure equal healthcare to areas where it is most needed. The use of a container and a mobile health bus is especially noteworthy. Mobile dental services have proven effective in several states in the USA in providing preventive and curative dental care in rural communities. ${ }^{[17]}$ They also provide training opportunities for senior dental students. However, although these services answer unmet dental needs of communities by offering temporary relief, they do not provide continuous care for dental diseases that cannot be treated once only. ${ }^{[17]}$

This raises an important issue of the type of dental treatment that should be offered in community initiatives. Helderman and Benzian ${ }^{[18]}$ recommend a basic package of oral healthcare, consisting of urgent oral treatment, including extractions, affordable fluoride toothpaste and atraumatic restorative treatment, which involves the removal of soft decayed tooth tissue and replacing it with a glass ionomer cement, as a guiding framework for dental NGOs. However, this one-size-fits-all solution cannot be applied to all settings; an oral healthcare package should be tailored to suit the needs of each community.

In KZN, urgent treatment, i.e. tooth extractions, and more preventive oral healthcare, should be offered, including oral health education, and promotion and placement of fissure sealants for 6-year-old children. Mickenautsch et al. ${ }^{[19]}$ demonstrated that implementing atraumatic restorative treatment was not widely accepted in the SA context. Although it provided access to restorative treatment to people who previously did not receive any care, there were several barriers to its implementation, including a large patient load, insufficient supply of materials, operators' reluctance to adopt new techniques and patients' preference to extracting teeth rather than restoring them. This is further supported by Reddy and Singh, ${ }^{[15]}$ who promote preventive programmes rather than curative ones, and recommend oral health-promotion programmes at schools to instil good oral health behaviour at an early age. The mobile health bus and the container clinic can be considered suitable projects, as they offer this type of oral care package, which is simple, effective and inexpensive. This is in line with primary healthcare principles currently being adopted by the health system.

\section{Theme 2: Learning opportunities for dental therapy students}

The participants indicated that there could be several opportunities for students in their programmes. Three sub-themes emerged within theme 2: participation in community initiatives, adapting to a community-based setting and developing social responsibility.

\section{Participation in community initiatives}

Respondents were keen on students joining their initiatives, offering them a chance to expand existing projects, becoming part of their team and playing a role in sustainable initiatives (Table 2).

\begin{tabular}{|c|c|}
\hline Methods & Participants' responses \\
\hline $\begin{array}{l}\text { Use of a shipping container as a mobile } \\
\text { clinic }\end{array}$ & $\begin{array}{l}\text { 'We have a shipping container, converted into a mobile clinic. It has two parts, one in which we check vital signs, } \\
\text { assess weight, height, blood pressure, temperature and, for the actual treatment, we use the other. The container is } \\
\text { then taken to different schools and placed there, where we work until we are finished with all the children and then it } \\
\text { would be moved to another school.' (P1) }\end{array}$ \\
\hline Restructuring old premises & $\begin{array}{l}\text { 'We had a school here and our school was moved to a larger place. The premises became available and the next } \\
\text { service we thought that we could help the community with, was having a clinic.' (P5) }\end{array}$ \\
\hline Trust-funded clinic & $\begin{array}{l}\text { 'Another group of people started this clinic but handed it over to our organisation to run. About } 2 \text { years ago the } \\
\text { charitable trust of our organisation funded us for a new clinic in this community' (P6) }\end{array}$ \\
\hline $\begin{array}{l}\text { School turned into a makeshift clinic } \\
\text { during a weekend }\end{array}$ & $\begin{array}{l}\text { 'For example, if we are going to a community, we would go there and visit the place to see whether it is okay for us to } \\
\text { use, such as the classrooms or school facilities, and closeness to a tap, as we need water to set up a dental clinic.' (P4) }\end{array}$ \\
\hline Mobile health bus & $\begin{array}{l}\text { 'We decided to get a mobile health bus that takes healthcare to the people. We wanted to offer the types of health } \\
\text { services that parents can't really get to for their children. We wanted to provide a service at schools. We would park at } \\
\text { a school for at least } 1 \text { week. A learner is taken to the optometry section and a full assessment is done there, and then } \\
\text { move to the next section, which is primary healthcare, and then move to dentistry.' (P9) }\end{array}$ \\
\hline $\begin{array}{l}\text { Offering healthcare packs on health } \\
\text { awareness day }\end{array}$ & $\begin{array}{l}\text { 'Patients received a health pack, which included toothbrushes, toothpaste and soap. The participants were given gift } \\
\text { bags with sanitary pads, feminine products and oral hygiene products.' (P7) }\end{array}$ \\
\hline
\end{tabular}


NGOs welcome students as additional team members to assist them in their endeavours. Inviting students to join their projects demonstrates a need to expand the oral healthcare workforce in the NGO sector, as there are very few oral health workers who volunteer their services. This is further supported by Helderman and Benzian, ${ }^{[18]}$ who reported that the dental NGO sector is very small, with a maximum of 500 dental NGOs worldwide. Involving students in such projects on an ongoing basis creates a substantial workforce. This in turn contributes towards the long-term sustainability of NGO projects in the province, leading to better oral health outcomes of communities. Students can thus play an important role in enhancing the functionality of NGOs and private sector teams, which ultimately shows the reciprocal nature that can be developed with this association.

\section{Adapting to a community-based setting}

The participants believed that students could benefit by meaningful engagement with communities through real-world experiences, learning to work with available resources and a chance to develop non-technical skills (Table 3).

Students who are engaged in community-based training gain meaningful learning experiences. In addition to improving clinical skills in community settings, they are exposed to pathological conditions that they normally do not encounter in the hospital setting. These conditions can often be observed because patients delay seeking affordable dental treatment. Students also learn to adapt to work environments with limited resources. This provides them with a good learning experience, as not all work environments correspond to the ideal training site with the latest equipment and materials that they have become accustomed to.

Students also have opportunities to develop non-clinical skills, such as learning to treat patients with respect, compassion and care, irrespective of their background. In doing so, they attain graduate competencies of being a caring health professional who communicates well with patients of different cultures, as advocated by the institution. This type of learning is explained by the experiential learning theory that supports students being directly involved in the learning process instead of passively imbibing information from the lecturer. ${ }^{[20]}$ Learning is directly linked to the activity performed by the student, the context and culture in which it occurs, the interaction with peers and the community, and the reflection of this experience. In this way, learning is situated and not abstract. ${ }^{[20]}$ This is further supported by a study conducted among dental students participating in NGO projects, reporting that they had opportunities of putting into practice the theory they learnt in school, improving their dental skills, observing real-life cases away from an academic setting and networking with professionals in the field. ${ }^{[21]}$

Table 2. Participation in community initiatives

\section{Learning opportunities \\ Opportunity to expand existing project}

Students viewed as potential team members

Become role players in a sustainable project

Slow integration of students into current programme

\section{Participants' responses}

'Dental students can be a part of our health day initiative and screening. They have suggested that they would like to do minor procedures, such as extractions and cleaning, if provided with the equipment. There is room for the project to grow and an opportunity for them to start their own referrals to the appropriate clinics.' (P7) 'We run a dental clinic once in 2 weeks on a Friday. This clinic is run by a dentist, who volunteers his services. This can be a good opportunity for dental students to come on board, so we can offer dental services every Friday, as there is a great need for this in the community we serve.' (P5)

'The oral hygienist comes only once when we are at the school, so if your students are here, it would be much better. I know we will complement each other when they come. Maybe I will say this child needs an extraction, but they might say that this tooth is strong, you can still save it by cleaning and filling it. So I think it will be great, and the oral hygiene will improve.' (P1)

'Dental students can be a part of our health expo on an ongoing basis. It would be nice if dental students have a mobile clinic to do simple procedures such as tooth extractions. I can arrange an afternoon only for dental procedures.' (P2)

'Maybe we could get them to do the screenings from March to June and maybe scalings and, later in the year, they could join us for dental extractions when they are more competent. So they can get practical experience from beginning to end. So, you can draw up guidelines on how and where and when they can join us and as we grow, we can see how we can fit them in more.' (P9)

Table 3. Adapting to a community-based setting

\section{Learning opportunities}

Real-world experience

Learning to work with limited resources

Developing non-technical skills

\section{Participants' responses}

'It gives them exposure to the outside world - not only being in the classroom or on campus. On campus you may be able to see all the theoretical things, and on the outside, in the field, you are seeing practical work, where you would see many diseases that you may not physically see at your place of study' (P4)

'In the rural areas they have an opportunity of learning more and getting an experience with different rural communities. I did my primary healthcare at a rural area and I got that experience.' (P1)

'I can improvise when I am in the community because I know that I will not be getting everything I'm used to, but to get a person healed or cured or get him some help, you need to work with what you have. So that is why I say when I am here, I come to the level of the people.' (P1)

'I would just like these students to be committed and dedicated to the work and to be able to follow the ethos that is there. We would like patients to be treated with absolute kindness, respect and understanding.' (P6) 


\section{Developing social responsibility}

Through participation in community-based initiatives, participants believed that students could gain a deeper understanding of social needs and plights and hence could develop a sense of social responsibility (Table 4).

The World Health Organization (WHO) defines social accountability of institutions that train health professionals as an obligation to direct their education, research and service activities towards addressing priority healthcare needs of communities and nations. ${ }^{[22]}$ Exposing students to NGO projects in communities, allows the institution to achieve its goal of being more socially engaged. It exposes students to the realities of rural communities and the need for oral health services, which may inspire students to want to service these areas fter they have graduated. This is further supported by Hood, ${ }^{[20]}$ who reports that when students participate in community-based programmes, it increases the number of graduates who wish to practise in rural, underserved areas.

Participation in NGO projects inculcates in students a sense of giving back to the community by volunteering their services to these projects. By participating, they learn how to conduct such projects and can also inspire inhabitants to initiate this in their own communities or in those where they see a dire need for health services. This is supported by the growing consensus in the dental profession that its members have a moral responsibility to serve the public good by providing expert dental care to all in need. ${ }^{[8]}$ However, it is unrealistic to expect a qualified dental professional to consciously provide care for the underserved or under-privileged if this was not given any importance in their training. Therefore, providing opportunities for students to participate in NGO projects can instil values of humanitarianism and professionalism.

\section{Theme 3: Support provided}

Participants reported that they could provide support, such as an enabling mentorship, transport and sustenance (Table 5).

Participants were willing to provide orientation, training and support to assist students. While some were prepared to provide support, others regarded this as a barrier to student participation. An enabling environment is very important for active student learning. This is further supported by Gordon, ${ }^{[23]}$ who confers that a supportive environment is essential in building clinical competencies in students.

Moreover, these projects can make a real difference in communities if they are supported by local health systems, co-ordinating their programmes with that of the health system through a small ongoing partnership. In this way, there could be sharing of skills, personnel and resources, as volunteers on the ground assist public healthcare workers by reducing the daily patient load and, through sustainability, strengthen the health system. ${ }^{[24]}$

\section{Theme 4: Creating interprofessional learning opportunities}

Every participant reflected on the need for students from other disciplines to join their programme (Table 6).

Interprofessional education occurs when $\geq 2$ health professional students learn with each other to educate and manage patients. ${ }^{[24]}$ Combining community-based training and interprofessional learning is ideal and a

Table 4. Developing social responsibility

\begin{tabular}{l} 
Learning opportunities \\
\hline Addressing the community's needs
\end{tabular}
Participants' responses

'Oral health and oral hygiene are vital and really needed in this community. Dental students can do dental screening, can go to school, do oral health education. A dental programme can be conducted during the school holidays, but you need to give advanced notice and we can advertise it so that the community is aware of it.' (P3) 'There is a real need for dental human resources. If we can get dental students coming in and supervised, then we can get the patients.' (P6)

'They can give oral hygiene education and community service. Oral health education is really needed in this community. Students can demonstrate to them the correct way to brush their teeth and educate them on diseases that affect the teeth.' (P8)

Social accountability 'We just want to give our people that come to our clinic service, bearing in mind humanity. So we give humane services to these people, remembering also that there can be no double standards of this care. There cannot be one care for you and your family and another one for the people coming there.' (P6)

Instilling volunteerism 'To come and see what the outside world looks like, to interact with the community and see what their needs are. When you get out into society, as a professional, you would also be able to offer that kind of compassion and service to them, maybe not because you want to earn a salary, but to have that same love to serve humanity as we do.' (P4)

Table 5. Support for student training

\begin{tabular}{ll}
\hline Support & Participants' responses \\
\hline Student safety & 'If they need our help, we will help to orientate them. If their safety is a problem, we will phone them and inform \\
& them not to go in, as there may be unrest in the community.' (P1) \\
Transport and sustenance & 'Providing transport to students to and from the health expo. Provide them with a meal.' (P2) \\
Professional support and guidance & 'We also have the professional personnel to back us up if there are complications such as breakage of a tooth. The \\
& professional will be there to extract it and relieve the issue or symptoms of the patient.' (P4) \\
Mentorship & 'Senior medical/healthcare professionals could attend the events and provide guidance and advice to students. \\
& The content comes from senior students who have attained knowledge from academic and skills training.' (P7) \\
Enabling environment & 'We provide a platform for all healthcare students to participate in this initiative.' (P7)
\end{tabular}




\section{Research}

growing trend in educational institutions. ${ }^{[25]}$ NGOs indicating the need for services of other health professionals emphasise the need for health professionals to work together for the benefit of society. Thus, NGO projects provide a platform for all student health professionals to learn to work effectively in interprofessional teams. However, these opportunities need to be created by academics from individual disciplines who have acquired humanitarian values.

\section{Theme 5: Perceived barriers}

The participants agreed that there were some barriers that could hamper student participation (Table 7).

In this study, it was noted that transport to the areas where NGO projects occur, is a huge barrier. These NGO projects can be beneficial for student healthcare professionals and institutions. Therefore, the institution should consider providing support.

Orientation and training is an important aspect of the principles of experiential learning ${ }^{[5]}$ If students were to participate in these programmes, they first need to be orientated towards and informed about the project and the background of the NGO to develop a good attitude before they commence. This is in line with the principles of experiential learning: the intention of enabling experience to be transformed into knowledge with proper planning and preparedness; orientation and training; reflection through monitoring; and evaluation to ensure successful learning experiences. ${ }^{[5]}$ It is important for students to realise that volunteering is sharing done with good intention, compassion and concern extended to the less privileged in a respectful manner. Likewise, where NGOs are not sure

Table 6. Creating interprofessional learning opportunities

\begin{tabular}{l} 
Opportunities \\
\hline Need for rehabilitation services \\
Holistic patient management
\end{tabular}

Holistic patient management

Patient screening

Sharing the workload

Joining an existing programme

Restarting discontinued services 'We started a programme with physiotherapy and optometry students; optometry is continuing, but with physiotherapy and occupational therapy - it could not be sustained because of lack of manpower. I would really love it if these health professional students could continue like optometry' (P6)

'We also had students from the eye clinic to come to help us, service us, but unfortunately some of our projects have faded away. We want to reintroduce this eye clinic and try to make it a success, where students can get exposure to serving the communities.' (P4)

Job opportunities 'Optometry, we really need the services of optometry students, there are also job opportunities for newly qualified optometrists.' (P9)

Cross-cultural experience

\section{Participants' responses} occupational therapy, come on board, but to get people to come out over the weekend is difficult.' (P2)

'We would like to collaborate with many other healthcare professionals, such as optometrists, physiotherapists, occupational therapist, to provide holistic care.' (P7)

conducted on the same day.' (P3)

'Optometry students are also needed. They can come to schools and conduct eye tests and refer some patients back to the eye clinic at the hospital.' (P1)

(student pharmacists) who want to volunteer their time and effort, then obviously they are welcome to do so. (P4)

We do have an eye clinic which is run by an optometrist who comes in every 2nd Friday, so optometry students are welcome to be a part of this. We get pharmacists who come from the main hospital to dispense medication here pharmacy students can also benefit and learn from this.' (P5)

'There are opportunities for students from other disciplines to come to observe how it is to work in different communities.' (P8)
Table 7. Perceived barriers

\begin{tabular}{ll}
\hline Possible barriers & Participants' responses \\
\hline Transport & 'We also use one transport, we share the transport with others from the hospital and there may be no or limited \\
space for students.' (P1) \\
'Transport has been a huge barrier to participation, as it's difficult to get a large group of people to and from the \\
venues. The healthcare facilities are located on different campuses and have different term times, which impacts \\
collaboration. Our events are held over the weekend, which limits student availability/participation.' (P7) \\
'The funding for travelling and sustenance of these students would not be part of our funding.' (P9) \\
'The students need to be community orientated. Sometimes you get students, but they do not co-operate, because \\
in the community you have to come down to the level of the people and their working conditions are not like in \\
the institutions.' (P1) \\
'I would not want smoking in there and I would not want people sitting there and laughing at each other or be on \\
their cell phones and coming there to think that it is a holiday.' (P6) \\
'Students must learn to treat patients with compassion and respect.'(P5) \\
'I am sceptical about allowing students to actually work on patients - doing tooth extractions. We cannot let \\
students work on patients - we want people who are qualified to work on patients.' (P8)
\end{tabular}


of student capabilities, they need to be orientated and informed of the scope of practice of a dental therapist.

The abovementioned themes show that there are several untapped learning opportunities for health professional students outside the homogeneity of the university environment. The private sector and NGOs contribute to supplementing the public health system by improving access to underserved communities through their innovative concepts of service delivery. These projects can also provide authentic learning experiences for health professional students at an interprofessional level, where knowledge is created through active participation, reflection and transformation of the experience. ${ }^{[6]}$ Participation in these community projects can benefit them professionally and personally. It could also inspire students to play an advocacy role in support of healthcare for all. Student participation in community-based projects is mutually beneficial to NGOs and private organisations, as they can significantly contribute to increasing their workforce members, demonstrating a reciprocal nature of this association. However, these learning opportunities must be conducted following the principles of experiential learning. ${ }^{[5]}$

\section{Study strengths and limitations}

This study highlights the meaningful learning opportunities available at NGOs and in the private sector for students to experience the realities of poor communities, become more socially aware, awaken their sense of social accountability and instil humanitarianism. The study findings can feed into planning and implementation of community-based education activities for dental therapy students. There is very little published work on NGOs and the private sector; hence, this study provides useful data and a better understanding of the role NGOs play in society.

It is acknowledged that this study was conducted using only NGOs and private enterprises known to the researcher and restricted to those in KZN. Another limitation was that the researcher did not interview the volunteer healthcare workers directly involved in patient care in these organisations' projects to obtain their views on volunteerism and challenges. More research is therefore required in this area.

\section{Conclusion}

This study showed that there are many opportunities in the private and NGO sectors that could provide support for community-driven learning initiatives for undergraduate dental therapy students.
Acknowledgements. The authors acknowledge the participation of stakeholders from the private and NGO sectors.

Author contributions. IM: data collection, data analysis and conceptualisation. SS: refined the methodology and oversaw the write-up.

Funding. None.

Conflicts of interest. None.

1. Department of Health. Annual Report 2013/14. Pretoria: DoH, 2014.

2. Loots $\mathrm{H}$, Hertzog E, van den Heever A, et al. Identifying the determinants of and solutions to the shortage of doctors in South Africa: Is there a role for the private sector in medical education? A report commissioned by the Hospital Association of South Africa (HASA). Econex Competition and Applied Economics 2015:1-56.

3. Statistics South Africa. Census 2011 Statistical Release. Pretoria: Stats SA, 2011.

4. Piotrowicz M, Cianiara D. The role of non-governmental organisations in social and health systems. Przegl Epidemiol 2013;67:69-74.

5. National Society for Experiential Education. Eight Principles of Good Practice for all Experiential Learning Activities. 1998. https://agsci.oregonstate.edu/sites/agsci/files/main/students/EightStandards.pdf (accessed 13 August 2018)

6. Kolb AY, Kolb DA. Handbook of Management Learning, Education and Development. New Jersey: Sage, 2008. 7. Deogade SD, Naitam D. Discipline-based versus compency-based education in dentistry. Eur J Pharmaceut Med Res 2016;3(1):269-272.

. Karim A, Mascarenhas AK, Dharamsi S. A global health course: Isn't it time? J Dent Educ 2008;72(11):1238-1246 9. Phelophepa Health Train. https://transnet foundation.co.za.portfolio.html (accessed 15 June 2018).

10. Braun V, Clarke V. Using thematic analysis in psychology. Qual Res Psychol 2010;3(2):77-101. https://doi org/10.1191/1478088706qp063oa

11. Creswell J. Research Design: Qualitative, Quantitative and Mixed Methods Approaches. 4th ed. London: Sage 2014.

12. Anney VN. Ensuring the quality of findings of qualitative research: Looking at trustworthiness criteria. J Emer Trends Educ Res Policy Stud 2014;5(2):272-281.

13. Hobdell MH. Health as a fundamental human right. Br Dent J 1996;180:267-270.

14. Van Wyk P, van Wyk C. Trends in dental caries prevalence, severity and unmet treatment need levels in South Van Wyk P, van Wyk C. Trends in dental caries prevalence, severity
Africa between 1983 and 2002. S Afr Dent J 2010;65(7):310-314.

15. Reddy M, Singh S. Dental caries status among six-year-old children at health promoting schools in KwaZuluNatal, South Africa. S Afr Dent J 2015;70(9):396-401.

6. Van der Merve W, Swart I, Hendriks J. Faith-based organisations in the context of social welfare and developmen in South Africa: Towards a conceptualisation. J Soc Work 2009;45(2):25-139.

17. Skillman SM, Doescher MP, Mouradian WE, et al. The challenge of oral health services in rural America. J Pub Health Dent 2010;70:S49-S57.

18. Helderman $\mathrm{W}$, Benzian $\mathrm{H}$. Implementation of a basic package for oral care: Towards reorientation of denta volunteers and their NGOs. Int Dent J 2006;56(1):44-48.

19. Mickenautsch S, Frencken J, van't Hof M. Factors inhibiting the implementation of the atraumatic restorative treatment approach in the public oral health services in Gauteng province, South Africa. J Appl Oral Sci 2007;15(1):1-8.

20. Hood JG. Service-learning in dental education: Meeting needs and challenges. J Dent Educ 2009;73(4):454-463.

21. Withers $\mathrm{M}$, Browner $\mathrm{CH}$, Aghaloo T. Promoting volunteerism in global health: Lessons from a medical mission in Northern Mexico. J Commun Health 2013;38:374-384.

2. Boelen C, Heck J. Defining and Measuring Social Accountability of Medical Schools. Geneva: World Healt Organization, 2014. http://whqlibdoc.who.int/hq/1995/WHO_HRH_95.7.pdf (accessed 18 June 2016).

23. Gordon NA. Learning experiences of oral hygiene students in the clinical environment. Int J Dent Hygiene 2013;11:267-272.

24. Dickson M, Dickson G. Volunteering: Beyond an act of charity. J Can Dent Assoc 2005;71(11):865-869.

25. Connors K, Seifer SD. Interdisciplinary models of service-learning in higher education. 2005. http://www. servicelearning.org/instant_info/fact_sheets/he_facts/interdisciplinary (accessed 14 August 2018). 